\title{
O Brasil e a sombra dos Estados Unidos: discursos sobre a autodeterminação nacional em Eduardo Prado e Araripe Júnior
}

Brazil and the Shadow of the United States: Speeches on National Self-determination in Eduardo Prado and Araripe Júnior

Carlos Henrique Armani*

\section{RESUMo}

O objetivo do artigo é apresentar alguns discursos elaborados por dois intelectuais brasileiros de fim do século XIX e princípio do século XX. O primeiro deles é o monarquista Eduardo Prado; o segundo, o republicano Araripe Júnior. A opção por apresentar algumas ideias desses dois autores se justifica não somente por suas diferenças nos modos como entendiam o Brasil e sua aproximação aos Estados Unidos, mas também porque Araripe Júnior foi um leitor e crítico do pensamento monarquista e, particularmente, do pensamento de Prado. Apesar das diferenças entre eles, havia em comum em suas abordagens um problema de ordem valorativa e moral que deveria resolver-se por meio de um retorno ao passado brasileiro ou de sua ruptura com ele: o desenvolvimento efetivo de uma autonomia da nacionalidade brasileira. Palavras-chave: identidade nacional; autodeterminação nacional; intelectuais brasileiros; virada para o século XX.

\section{Abstract}

The aim of this article is to present some speeches elaborated by two Brazilian intellectuals of the late 19th and early 20th century. The first of them is the monarchist Eduardo Prado; the second one, the republican Araripe Júnior. The option to present some ideas of these two authors is justified not only by their differences in the ways they understood Brazil and its approach to the United States, but also because Araripe Júnior was a reader and critic of the monarchist thought and, particularly, of Prado's thought. Despite the differences between them, there was in common in both approaches a problem of moral and value order that should be resolved through a return to the Brazilian past or through its rupture with it: the effective development of an autonomy of the Brazilian nationality.

Keywords: national identity; national self-determination; Brazilian intellectuals; the turn to the 20th century.

\footnotetext{
* Universidade Federal de Santa Maria (UFSM), Santa Maria, RS, Brasil. carlos.armani@gmail.com $<$ https://orcid.org/0000-0003-4855-6115>
} 
Na passagem para o século XX, os Estados Unidos se converteram em uma das principais nações da cena geopolítica, econômica e discursiva no Brasil, o que impulsionou as polêmicas relativas aos novos vínculos deste país em relação ao gigante do norte e à perda (ou não) de sua autonomia econômica, política e até moral. Como Oliveira Lima escreveu em 1899:

No Brasil, fala-se muito bem ou muito mal dos Estados Unidos. Apontam-nos os seus admiradores como o único modelo a seguir sem discrepâncias, o melhor figurino a copiar nos mais ligeiros pormenores, sem cogitarem da diferença dos meios, das respectivas tradições nacionais e dos costumes de cada povo. Os seus detratores culpam-nos de todos os crimes, desde a ambição devoradora de terras e de nacionalidade, até a corrupção política e social mais desbragada. (Oliveira Lima, 2009, p. 51)

Esse breve enunciado constatativo de um clima de opiniões pode ser aplicado para diversos intelectuais brasileiros finisseculares, inclusive para o próprio Oliveira Lima, que era um admirador cauteloso dos Estados Unidos. Se a nação do norte tenderia à dominação universal e "à ambição devoradora" sob o eufemismo de proteção das democracias nas Américas, ou se ela deveria ser imitada "nos mais ligeiros pormenores", eram alguns dos principais tópicos das polêmicas realizadas pelos intelectuais que reivindicavam a urgência de pensar o caráter nacional dos Estados Unidos e refletir também acerca do próprio Brasil como um ser moral autônomo. Nesse sentido, os Estados Unidos se tornaram um dos principais exteriores constitutivos do Brasil, para usarmos uma expressão de Jacques Derrida (2001), ${ }^{1}$ presentes de modo recorrente no pensamento de intelectuais que tinham como preocupação central pensar essa nova forma de relação internacional e nacional entre os dois Estados nacionais. Foi por meio dessas identidades contrastantes que alguns autores expressaram os riscos e benefícios da aproximação do Brasil aos Estados Unidos. O que deveria ou não ser imitado, se é que havia imitação; como essa nova nação deveria ser pensada em termos de democracia; quais eram os problemas internos do próprio Brasil, e o que faria efetivamente do Brasil uma nação autodeterminada, eram questões para as quais alguns escritores encontraram respostas e não poucas dúvidas. ${ }^{2}$ Tais problemas eram parte de um contexto político-intelectual que emergiu com a proclamação da República, do qual sobressaíram, segundo Alonso, "duas identidades políticas relacionais: monarquistas-aristocratas e republicanos-ascendentes", o que resultou em um "enfrentamento a um só tempo político e simbólico" (Alonso, 2009, p. 
133-134). De um lado estavam os republicanos que atrelavam o Império à decadência e se "lançaram à edificação de uma tradição republicana que suplantasse a imperial"; de outro, monarquistas que se "puseram a resgatar a tradição imperial, invertendo os vetores: o regime deposto virou um ápice de civilização e a República, sua ruína" (Alonso, 2009, p. 134).

Nosso objetivo, neste artigo, é apresentar alguns discursos elaborados por dois intelectuais brasileiros da virada para o século XX, enfatizando suas posições políticas em relação à aproximação do Brasil aos Estados Unidos, o que resultou em uma acirrada disputa pelo sentido da autodeterminação da nação tropical e seus limites: ${ }^{3}$ o monarquista Eduardo Prado e o republicano Araripe Júnior. A opção por apresentar algumas ideias desses dois autores se justifica não somente por suas diferenças nos modos como entendiam o Brasil, mas também porque Araripe Júnior foi um leitor e crítico do pensamento monarquista e, particularmente, do pensamento de Prado. ${ }^{4}$

Eduardo Prado fez o elogio do passado monárquico do Brasil e entendeu o presente republicano e mesmo, potencialmente, o futuro como sintomas de atraso e de dependência do Brasil frente às novas forças políticas emergentes (os Estados Unidos), o que implicaria a perda de autonomia da nação tropical. Araripe Júnior fez uma crítica forte ao passado monárquico e preconizou uma nova independência do Brasil - sobretudo dos valores europeus, arraigados na continuação dos ideais monárquicos portugueses -, cujas relações com os Estados Unidos implicariam um reforço dessa independência. Em comum, nos dois enfoques da questão da dependência e da independência havia um problema de ordem valorativa e moral que deveria resolver-se por meio de um retorno ao passado ou da ruptura com ele: o estabelecimento efetivo de uma autonomia da nacionalidade brasileira.

Como sabemos, o conceito de autonomia é central na configuração do humanismo moderno, o qual, por meio de algumas filosofias da história, foi mobilizado para constituir o sentido do singular-coletivo nação. ${ }^{5}$ Segundo Renaut (2004, p. 10), o que define intrinsecamente a modernidade é "a maneira como o ser humano nela é concebido e afirmado como fonte de suas representações e de seus atos, seu fundamento (subjectum, sujeito), ou ainda, seu autor", uma clara contraposição à heteronomia, em que é a "exterioridade que dita a lei" (Renaut, 2004, p. 13). Tal exterioridade poderia ser proveniente tanto da "ordem das coisas no mundo", como também da tradição que se impõe ao indivíduo "sem ter sido por ele escolhida e nem ter sido fundada em sua própria vontade" (Renaut, 2004, p. 28). Pensar em um determinado presente - no caso, a virada para o século XX -, o passado e o futuro da nação como algo 
produzido pelos seus próprios membros, o conjunto da comunidade como autor de seu próprio destino, seria um princípio fundamental da liberdade e, portanto, de sua própria autodeterminação. ${ }^{6}$ Se ela estivesse ameaçada, toda a nação o estaria também.

Um aspecto importante de ordem teórica ao qual gostaríamos de fazer menção antes de dar prosseguimento à investigação do pensamento de Prado e de Araripe é que entendemos o discurso (ou o pensamento) desses autores não somente como performances da linguagem, mas como um esforço para pensar problemas reais muito sérios para eles (e, por que não dizer, para nós), o que tornava os discursos em torno da nação e de sua autodeterminação, por assim dizer, problemas existenciais no sentido mais incisivo do termo. Em seu lançar-se para o mundo, tais autores não estavam fazendo digressões sobre um objeto ideal, ainda que o futuro como possibilidade de realização nacional fosse um tópico importante de suas polêmicas - e, mais importante ainda, como um modo de sustentar a possibilidade de uma autonomia que não seria condicionada por uma ordem natural, fosse ela "tradição", fosse ela uma "lei natural". Havia um problema tangível, merecedor de enunciados que se pretendiam estabelecer como verdadeiros para descrever e representar a realidade que, em seu universo de significação, estava longe de ser apenas um apanágio discursivo. Sabemos que as discussões aqui trazidas ocorrem no âmbito da linguagem, mas isso não quer dizer que elas tenham sido estritamente linguagem. Como diz Quine, controvérsias ontológicas podem levar a controvérsias sobre a linguagem, mas "não devemos saltar à conclusão de que o que há depende de palavras. A traduzibilidade de uma questão em termos semânticos não é uma prova de que a questão é linguística" (Quine, 2011, p. 31). E complementa o autor: "ver Nápoles é carregar um nome que, quando prefixado às palavras 'ver Nápoles', produz uma sentença verdadeira; ainda assim, não há nada de linguístico em ver Nápoles” (Quine, 2011, p. 31). Não é muito diferente o que sugere Pocock para a história (Pocock, 2003, p. 36-37), ao afirmar que a "linguagem é referencial e alude a vários objetos. Ela alude a elementos de uma experiência da qual ela provém e com os quais ela torna possível lidar", além de aludir, também, "a instituições, autoridades, valores simbólicos e acontecimentos registrados que ela apresenta como parte da política dessa sociedade e dos quais deriva muito do seu próprio caráter", um “contexto linguístico" que indica "um contexto político, social ou histórico, no interior do qual a própria linguagem se situa" (Pocock, 2003, p. 36-37). Portanto, pensar as ideias e conceitos desses dois autores do fin-de-siècle não quer dizer que o que estamos pensando se restrinja apenas ao seu pensamento - uma circularidade infinita de remessas 
textuais. Diz respeito ao que eles estavam vivenciando como experiência de mundo e ao que vivenciamos como experiência de mundo a partir de nossa relação com seus textos e com o mundo que eles evocam e que nos afetam.

\section{O ElOgio Ao PASSADO E A DEPENDÊNCIA PRESENTE}

Comecemos pelo autor que elogiava o passado monárquico e entendia a República como um atraso e um modo de dependência do Brasil às leis ditadas do exterior: Eduardo Prado.

Eduardo Prado (1860-1901) foi membro de uma rica família de cafeicultores de São Paulo e um dos principais intelectuais de fins do século XIX. Formou-se em Direito na Faculdade de São Paulo e trabalhou como jornalista e historiador. Prado ainda foi um dos fundadores da Academia Brasileira de Letras e sócio-correspondente do Instituto Histórico e Geográfico Brasileiro. Manteve sua vida dividida entre a fazenda do Brejão, no interior de São Paulo, e Paris. Não produziu uma obra muita extensa, em razão da morte por febre amarela que interrompeu a sua curta carreira intelectual, aos 41 anos de idade. Em termos políticos, o escritor foi um dos principais articuladores do Partido Monarquista em São Paulo, posição política da qual jamais se desfez. Como grande parte dos pensadores de fins do século no Brasil, Eduardo Prado foi um polemista notável, sobretudo depois da queda do regime monárquico, em 1889, quando sua posição enquanto intérprete da nação se definiu de modo mais preciso. Segundo Oliveira, "sua posição no mundo literário era destacada, fazendo parte de um grupo luso-brasileiro de intelectuais, integrado por Eça de Queiroz, Rio Branco, Ramalho Ortigão, Oliveira Martins, entre outros" (Oliveira, 1990, p. 107).

Mais conhecido na história intelectual brasileira como um dos primeiros escritores antiamericanistas, seu livro mais conhecido, A ilusão americana, publicado em 1893 e imediatamente censurado, foi um libelo agressivo contra os Estados Unidos. ${ }^{7}$

Nas primeiras linhas do livro podemos verificar sua pretensão:

Pensamos que é tempo de reagir contra a insanidade da absoluta confraternização que se pretende impor entre o Brasil e a grande república anglo-saxônia, de que nos achamos separados, não só pela grande distância, como pela raça, pela religião, pela índole, pela língua, pela história e pelas tradições de nosso povo. (Prado, 1961, p. 7) 
Parte significativa de A ilusão americana foi dedicada a aprofundar essa distância entre Brasil e Estados Unidos. As razões de um afastamento entre as duas nações não se circunscreviam à distância geográfica ou somente ao que seria a confraternização entre elas, mas abrangiam o que seria possível definir como o próprio ser nacional, que consubstanciava a raça, a religião, a índole, a língua e a história. Tratava-se de modos de civilização incompatíveis entre si. Em outras palavras: a ameaça à autodeterminação derivaria de uma condição política mais ampla, uma espécie de política das civilizações em que estavam em disputa dois modos de ser distintos: o monárquico e o republicano.

Ao falar da relação dos Estados Unidos com a América Latina e, particularmente, com o Brasil, a palavra de Prado era uma: ilusão. Ilusão dos países sul-americanos que eram regidos pelo pan-americanismo, alguns dos quais eram tratados como colônias, incapazes de "ser uma nação", como "protegida[s] e tutelada[s] dos Estados Unidos" (Prado, 1904a, p. 407-408). Para o autor, o governo norte-americano tinha má-fé e um "desprezo profundo" pela "soberania, pela dignidade e pelos direitos das nações latinas da América” (Prado, 1961, p. 55). E assim escreveu:

Quer-nos apresentar o governo americano aos brasileiros como o grande amigo das nações deste continente, como o seu protetor nato e, no furor disso demonstrar, há jornais brasileiros, de tão atrofiado patriotismo, que chegam a colocar o Brasil como que debaixo do protetorado americano, fazendo do Rio de Janeiro o vassalo e de Washington o suserano. É contra essa falsa ideia, contra esse esquecimento do pundonor nacional, que queremos reagir, relembrando aos nossos compatriotas o que tem sido a política americana. (Prado, 1961, p. 55)

Prado pretendia ser um escritor que tinha o compromisso com a lembrança da honra nacional. E sua denúncia do americanismo como política de Estado se assentava numa equação entre ilusão, falsa ideia e esquecimento. A ela se oporia a necessidade de lembrança compartilhada da autonomia, ou do retorno a uma autonomia que havia se perdido na república. Como afirmou o autor, seu livro foi escrito "sustentando a doutrina política de que o Brasil deve ser livre e autônomo perante o estrangeiro” (Prado, 1961, p. 193).

A metáfora da suserania e da vassalagem era utilizada pelo autor para evidenciar a relação assimétrica entre Estados Unidos e Brasil, de maneira que evocar uma relação social baseada na heteronomia era um modo de manter intocadas as hierarquias da dominação que seriam supostamente superadas com o surgimento da autonomia moderna aplicada às nações. ${ }^{8}$ Como poderia 
“a águia americana consentir que à sombra das suas asas poderosas, continuasse uma parte do livre solo americano debaixo do jugo espanhol?” (Prado, 1961, p. 68), perguntou o autor, quando falou da América hispânica. ${ }^{9}$ Estava em disputa, quando Prado contestou a doutrina, a questão da autodeterminação, porque ao fim, se o Brasil tivesse de apelar ao poder político ou econômico dos norte-americanos para manter sua independência, tal atitude seria uma demonstração de que não havia qualquer autonomia e que a dependência somente havia se deslocado para o lado mais ocidental do Atlântico norte. Era certo, para Prado, que a "bandeira estrelada é bastante grande para estender a sua sombra gloriosa de um oceano a outro" (Prado, 1961, p. 51). Para o autor, do colosso do norte não se poderia esperar nada, posto que ele não demonstrava "benevolência alguma para conosco ou para com qualquer República latino-americana” (Prado, 1961, p. 185).

Outro problema político que estava implicado na aproximação entre os dois países e, mais ainda, entre os Estados Unidos e os demais países latino-americanos, era a imitação: "o furor imitativo dos Estados Unidos tem sido a ruína da América” (Prado, 1961, p. 44). Ao fazer a denúncia da cópia, Prado demonstrou o quanto, para ele, a autodeterminação nacional estava ligada à capacidade de um povo criar e aplicar a lei a si próprio: "As sociedades devem ser regidas por leis saídas da sua raça, da sua história, do seu caráter, do seu desenvolvimento natural" (Prado, 1961, p. 45). Ao contrário do que havia ocorrido com os "países espanhóis da América", o Brasil teria "Obedecido à grande lei de que as nações devem reformar-se dentro de si mesmas, como todos os organismos vivos, com a sua própria substância, depois de já estarem lentamente assimilados e incorporados à sua vida os elementos exteriores que ela naturalmente tiver absorvido" (Prado, 1961, p. 45).

A independência, em 1822, não seria mais do que o "fato lógico do desenvolvimento da sociedade colonial; a monarquia mantida foi o respeito da tradição e a conservação do país na sua índole histórica que ninguém pode mudar" (Prado, 1961, p. 46). Imitar as leis políticas dos Estados Unidos era, nas palavras do autor, uma "ideia funestíssima" que levaria à desagregação de qualquer autodeterminação da nação: "copiemos, copiemos, copiemos, pensaram os insensatos, copiemos e seremos grandes! Deveríamos antes dizer: sejamos nós mesmos, sejamos o que somos, e só assim seremos alguma coisa" (Prado, 1961, p. 172). A autonomia, nesse sentido, estava associada a uma perspectiva de tempo futuro que permitiria ao Brasil reencontrar-se consigo mesmo, "tornar-se o que ele é", um devir futuro que indicava a necessidade de retornar ao ser para continuar a ser. Em discurso lido no Instituto Histórico 
de São Paulo, em 1898, Prado retomou a mesma ideia: “o desrespeito universal que nos desorganiza, que nos avassala e nos barbariza é, até certo ponto, o resultado da nossa ruptura com o passado, dessa lamentável emancipação da sua autoridade" (Prado, 1906, p. 124-125).

A principal denúncia apresentada por Prado em seu livro era de que a autodeterminação nacional das nações da América Latina - e do Brasil, em particular - estava ameaçada pelo primo loiro do norte, que pretendia fazer da América um "espaço vital" de sua geopolítica, sob o eufemismo de fraternidade americana, mantida pela Doutrina Monroe. As nações latinas da América, por sua vez, ao adotarem o modelo do norte - portanto, uma cópia -, contribuíram para o mesmo tipo de dependência que se aprofundaria - e do qual o Brasil deveria preservar-se. A metáfora da sombra usada por Prado indicava o caráter soturno da dominação do norte. Contra as luzes da autonomia nacional promovida pela ideia de racionalidade como fundamento da liberdade e da autofundação, apresentava-se a ameaça da vontade exercida de fora: "haverá coisa menos digna do que um cidadão desejar que a sua pátria não tenha a livre disposição dos seus destinos e esteja, quando se trata da escolha ou da mudança da sua forma de governo, dependente da vontade do estrangeiro?" (Prado, 1961, p. 21).

Eduardo Prado refutou a ideia de haver uma superioridade norte-americana em relação ao Brasil que pudesse justificar sua hegemonia - e aqui não somente à República, mas uma diferenciação substancial, em que estariam envolvidos os próprios eus nacionais em seu âmago - ao atribuir aos Estados Unidos certas qualidades negativas, como a violência física, da qual a Doutrina Monroe seria apenas uma consequência. Segundo Prado, os exemplos da violência norte-americana eram múltiplos e mais graves, como no México, na Guatemala, no Peru, no Panamá (notemos, casos em que tais nações eram repúblicas), onde os americanos "exerciam diariamente a sua brutalidade contra os pobres habitantes, desgraçados south Americans destinados a sucumbir ao contato do ianque" (Prado, 1961, p. 70). "Não há país latino-americano" (leia-se, não há república latino-americana), afirmou Prado, "que não tenha sofrido as insolências e às vezes a rapinagem dos Estados Unidos" (Prado, 1961, p. 94). Ainda referindo-se aos Estados Unidos, o autor afirmou que a civilização não era mensurada pelo aperfeiçoamento material, mas sim pelos seus níveis de elevação moral. Para ele, o "verdadeiro termômetro da civilização de um povo é o respeito que ele tem pela vida humana e pela liberdade. Ora, os americanos têm pouco respeito pela vida humana. Não respeitam a vida de outrem e nem a própria" (Prado, 1961, p. 173). 
O que se apresentava para Prado em termos de exterior constitutivo da nação brasileira era a violência, o desprezo pela vida humana em sua totalidade: "o espírito americano é um espírito de violência" (Prado, 1961, p. 175). O autor ainda evocou uma espécie de periodização natureza-cultura para definir o lugar dos Estados Unidos na fase primordial de desenvolvimento da civilização:

O período de desbravamento da terra, da derrubada das matas, do estabelecimento das primeiras culturas é, no interior e nas localidades novas, a idade do capanga; o escrivão, o promotor, o juiz, que vêm depois, expelem e eliminam o capanga. É a lei que substitui a violência. O espírito americano, infundido nas populações, é antes favorável ao capanga do que à gente do foro. (Prado, 1961, p. 175)

Prado via na aproximação entre as duas nações não somente a perda da autodeterminação que havia se originado na monarquia, mas um evolucionismo às avessas, posto que a aproximação à república, a ideia de constituir no Brasil um novo "Estados Unidos", era o equivalente linguístico de uma subordinação completa aos anseios do norte. Mais do que isso, uma forma de subordinação fática que implicava a violência física na dialética entre a suserania e a vassalagem, entre independência e dependência, entre autonomia e heteronomia. Para o autor, "somos um país sem existência, sem responsabilidade própria [...] Não deliberamos por nós, não praticamos nenhum ato espontâneo e livre [...] Somos uma dependência, um reflexo de alheia força e de estranha vontade" (Prado, 1904c, p. 419). Para ele, a solução para reconstituir a autonomia nacional era "suprimir a República para reconstruir a nação" (Prado, 1904b, p. 48).

Contraposto a Prado e pouco simpático às suas ideias, Araripe Júnior escreveu alguns textos de críticas fortes à manutenção dos vínculos brasileiros com a tradição europeia e reivindicou uma nova ordem democrática dos povos.

\section{A CRÍtica AO PASSADO E A AFIRMAÇÃO \\ DE UMA NOVA INDEPENDÊNCIA}

Tristão de Alencar Araripe Júnior (1848-1911), nascido no Ceará e membro da chamada "geração de 70", foi, com Sílvio Romero e José Veríssimo, um dos principais críticos literários da virada para o século XX. Cursou a Faculdade de Direito do Recife e vivenciou o "clima de rebeldia do Recife e de 
Fortaleza", onde participou de uma efervescente vida intelectual, ligado ao influxo das ideias liberais, entre as quais o abolicionismo e o laicismo (Coutinho, 1970, p. X). Morou em diversas cidades brasileiras, até estabilizar-se na capital federal em fins dos anos 1870. Segundo Ipiranga, Araripe "erigiu uma obra particular [...] que ainda é desconhecida de boa parte da intelectualidade”, dedicando-se, em seus artigos e livros, a defender "a autenticidade de nossa produção literária e a "necessidade de criação de novos critérios de valoração estética" (Ipiranga, 2016, p. 143). A exemplo de Eduardo Prado, Araripe foi um dos membros fundadores da Academia Brasileira de Letras em 1897, criada em contexto de apaziguamento dos comportamentos políticos pós-proclamação da República, a qual serviu para restringir a querela entre monarquistas e republicanos a um debate intelectual. ${ }^{10}$

Araripe Júnior foi um leitor atento de Prado, como se pode notar nas suas próprias palavras: "não cheguei a conhecer Eduardo Prado senão de vista. $\mathrm{Li}$, porém, todos os seus escritos" (Araripe Júnior, 1966a, p. 153). Uma parte importante de seus textos sobre os novos destinos que ele imaginava para as Américas e, dentro delas, para o Brasil, eram críticas à obra $A$ ilusão americana. Tal posicionamento do escritor cearense não era um ataque pessoal a Prado, mas uma crítica ao pensamento de autores que alimentavam o "desprestígio das democracias americanas", para os quais o Brasil seria "uma nação perdida, não só por força das instituições impossíveis que adotou, mas também porque a raça compósita, que forma a sua população, é uma raça decadente" (Araripe Júnior, 1963a, p. 327). Podemos notar o teor de suas críticas à Ilusão em um texto de 1896, em que ele se refere às "aspirações retrógradas" dos monarquistas e diz que não eram "outros os argumentos de Eduardo Prado nos seus escritos de propaganda monarquista e especialmente no livro A ilusão americana" (Araripe Júnior, 1963b, p. 87). Em 1909, em artigo publicado na Revista Americana, Araripe ainda comentava a repercussão que a obra $A$ ilusão americana havia tido no Brasil: "será tudo isto ilusão, como pretendia Eduardo Prado? [...] Ilusão ou obstinação, ou quem sabe diletantismo, foi o dele, escrevendo em ódio à República o seu detestável livro" (Araripe Júnior, 1966b, p. 51-52). ${ }^{11}$ Araripe afirmou que as dissidências que se "agitam em torno da palavra monroísmo são oriundas de sugestões maléficas" (Araripe Júnior, 1966b, p. 307). Em grande parte, segundo Araripe, "devemos esse resultado ao prestígio de um livro sensacional - A ilusão americana” (Araripe Júnior, 1966b, p. 307). E concluiu: "na corrente de sensações que teve por início a eloquência de Eduardo Prado [...] houve também uma ilusão. Penso, entretanto, que os 
leitores de Eduardo Prado foram guiados por um lado único da documentação histórica" (Araripe Júnior, 1966b, p. 307). ${ }^{12}$

O que Araripe tentou fazer em seus escritos políticos e, particularmente, em seus textos acerca da relação entre Brasil e Estados Unidos, foi apresentar outra tese sobre as novas configurações políticas das Américas diante da Europa. Araripe Júnior era um dos principais defensores de uma nova democracia nas Américas. $\mathrm{O}$ autor fez uma crítica que nos atrevemos a denominar como a morte de Deus em um sentido nacional e continental. De acordo com o escritor, "cada povo conserva no semblante o estigma de seu deus. Este fato, que é verdadeiro para as nações do Oriente e do Ocidente europeu desaparece desde que transpõe o oceano e se considera a colmeia americana" (Araripe Júnior, 1963b, p. 85). Os "povos recentíssimos" não mantinham em seu rosto "a máscara de nenhuma antiga divindade", posto que as nações do velho continente "não souberam ou não puderam premunir-se contra a misteriosa palingenesia transoceânica" (Araripe Júnior, 1963b, p. 85).

E continua:

Um dia os pioneiros da nova idade, ficados nas praias das duas Américas, retirando os olhos da mãe-pátria, viram que a fisionomia dos imigrantes, companheiros de tormentos, não era a mesma de outrora, e que as primitivas divindades não se tinham movido de seus antros para acompanhá-los na viagem aventurosa à terra dos incas, das manoas, dos eldorados. Novos continentes, novos deuses! Os deuses autóctones da América, os companheiros de Cortês, de Almagro e de Pizarro haviam-no sepultado nas águas do Titicaca. (Araripe Júnior, 1963b, p. 85-86)

A América, que havia criado novos deuses, ou seja, novos valores políticos e morais, tinha de romper com o passado colonial, simplesmente porque não havia razão para depender das nações europeias. Os velhos deuses "irritam-se na decrepitude das instituições que mantêm, na aflição da irresolubidade [sic] dos problemas econômicos que os tortura, pregam a violência e armam flibusteiros contra todas as nações incipientes" (Araripe Júnior, 1963b, p. 86). Para o escritor, os europeus renegavam seus descendentes porque não os podiam governar e a "política nefanda ordena aos seus sábios que inventem teorias de anátema contra as raças inferiores", sob o pretexto de "degenerados, mestiços e, portanto, condenados” (Araripe Júnior, 1963b, p. 86). Ironicamente, Araripe afirmou que, para aqueles que estavam fora do grupo jurídico das nações europeias, "guardas dos direitos da civilização, não há salvação possível. Elas 
formam o povo sagrado [...] Na América, na Austrália, nos países conhecidos pela denominação de coloniais, a escravidão ou a depredação" (Araripe Júnior, 1963b, p. 86). Nesse sentido é que se verificaria a tentativa de restituir-se, por meio da força, o "estigma dos antigos deuses, a máscara do dinasta que os costumes democráticos da livre América eliminaram do nosso rosto" (Araripe Júnior, 1963b, p. 87). Araripe estava falando dos novos valores que emergiriam na constituição das nações na América, o continente do futuro na terminologia hegeliana. ${ }^{13}$ Sua história como nações desenvolvidas e plenas seria realizada no século vindouro, que não seria mais europeu. Tais nações eram independentes e assim o seriam. Um retorno ao passado seria um modo de restituir a dependência que teria marcado o ethos colonial.

Mas em que medida Araripe pensava o americanismo da Doutrina Monroe como uma senha para entrar nas discussões sobre as Américas nesse contexto e pensar o problema da autonomia nacional? Ela era uma justificativa para a dominação do Brasil e, de modo mais abrangente, da América do Sul, ou era uma nova convicção política e moral de efetiva independência dos povos das Américas, destinada a servir para destruir os valores do passado europeu no Novo Mundo?

Em suas palavras: "Diz-se que a doutrina aludida é a boca de Gerionte, pela qual a América do Norte há de engolir as nações da América do Sul" (Araripe Júnior, 1966c, p. 50-51). Para ele, os Estados Unidos não encontrariam utilidade na conquista territorial dos países latino-americanos. Araripe entendia que os Estados Unidos, imersos em uma nova conviç̧ão política, não seriam imperialistas, tal como o foram Inglaterra e Alemanha. Com o começo do século XX, havia surgido uma nova disposição para as nações, contra a qual era escusado qualquer esforço de oposição. Para o autor:

Não se trata mais de ambições prepotentes, nem dessas mesquinhas leis de equilíbrio europeu... Amanhã, o que se debaterá é o equilíbrio dos continentes: a transformação do direito internacional, de mediterrânico em transoceânico: o estabelecimento de princípios que sirvam de base à nova jornada que o mundo vai empreender sob os auspícios de uma intercorrência industrial, de que os gregos e os romanos não houveram sequer o pressentimento: enfim, a conquista democrática do universo. (Araripe Júnior, 1966c, p. 50)

A Doutrina de Monroe não seria mais do que um dos instrumentos para a garantia dessa conquista. Araripe assim escreveu: 
A proclamação da doutrina de Monroe constitui apenas a exibição de um aparelho de defesa à democracia ameaçada. Gritam porque o temem; e temem-no porque veem quanto será fácil a esse instrumento transformar-se no critério futuro do mundo civilizado, no expurgador dos vícios que atentam em ambos os continentes contra o sossego dos diversos agrupamentos, e contra o desenvolvimento das virtudes ingênitas à humanidade e falseada [sic] pela desgraçada aplicação que se tem dado ao espírito mercantil. (Araripe Júnior, 1963c, p. 99)

Para o autor, a recepção do americanismo de Monroe no Brasil era positiva para a nacionalidade. Contra ele, gritaram os elementos "coloniais" e "retrógrados" ainda conectados profundamente "aos sindicatos protegidos pelo leopardo britânico" (Araripe Júnior, 1963c, p. 96). Segundo Araripe, a ideia de uma nova ordem internacional transoceânica significava a superação da dependência do Brasil em relação aos valores europeus e, de modo particular, ao imperialismo inglês, que estava em "declínio mundial" (Araripe Júnior, 1966c, p. 52). Se havia uma ameaça à autodeterminação nacional brasileira, ela era proveniente do passado brasileiro, ancorado em instituições monárquicas que não podiam conduzir o Brasil a uma efetiva democracia mundial, como o autor preconizava ao falar sobre a conquista democrática do universo. Araripe entendia que a América do Sul e particularmente o Brasil ainda não haviam se estabilizado para uma efetiva realização nacional. Contudo, entendia que tais condições eram parte de um processo de constituição da própria nação. Expurgar os vícios que ainda acompanhavam tais nações era um exercício para o futuro, que garantiria a efetiva independência das nações sul-americanas. Segundo Araripe

Não estou longe de pensar que a América do Sul precisa por seu próprio interesse de mais ordem do que a que até hoje tem havido; mas também é necessário que a responsabilidade das desordens se divida entre todos aqueles que têm concorrido para as erupções revolucionárias. Ao constituirmo-nos em nações, tivemos forçosamente de agitar-nos, e as agitações nestes casos não podiam deixar de ser cruentas, nem podiam evitar injustiças. Eis o nosso crime, e que ainda não se apagou de todo em algumas regiões da América. De que categoria, porém, deve ser o crime daqueles que, à fiúza de capitais aqui empregados, têm por mais de uma vez atentado contra a nossa independência, contra os nossos instintos de progresso autonômico, contra a nossa dignidade de homens. (Araripe Júnior, 1963b, p. 88)

Ainda que houvesse um perigo no futuro, depositado no devir da própria realização da democracia nas Américas, Araripe reconhecia que tais nações 
eram independentes. Havia relações com o passado a serem superadas, mas essas relações não eram suficientes para obnubilar a independência das nações transoceânicas. Contra o discurso e a prática imperialistas da Europa, o escritor não encarava a Doutrina Monroe como uma ameaça à autodeterminação, o que parecia reforçar sua crença efetiva de que o Brasil era uma nação independente, ainda que marcada por crises comuns a todas as nações emergentes. A crise, nesse caso, era um sintoma da autonomia e da independência nacionais e não o seu contrário.

Araripe reforçou sua tese em texto sobre a Doutrina Monroe - já mencionado anteriormente -, no qual lançou mão de uma filosofia especulativa da história para retirar da doutrina seu peso doutrinário enquanto tal. Tais ideias se encontravam presentes em seus textos anteriores, publicados nos últimos anos do século XIX, ainda que menos formalizados do ponto de vista filosófico. A doutrina nada mais era do que o sintoma de um espírito histórico mais amplo. Para ele, os povos "deste lado do Atlântico" haviam chegado à sua "idade adulta imunes de certos vícios" e estavam "melhor aparelhados para representar os interesses gerais do mundo" (Araripe Júnior, 1966b, p. 309). E concluiu: "e esse fato, por si, constitui mais do que uma doutrina. Uma doutrina despreza-se, se não convém; mas uma lei suporta-se, aguenta-se. A lei impõe-se” (Araripe Júnior, 1966b, p. 309). O “monroísmo”, mais do que uma imposição dos Estados Unidos, seria parte de um fenômeno universal que teria atingido as Américas, do qual a doutrina seria apenas uma de suas manifestações particulares. Neste caso, Brasil e Estados Unidos estavam submetidos à mesma força ontológica que se apresentava em termos de devir histórico. Nas suas palavras:

Eis a razão por que não considero séria a oposição sistemática à ascendência do monroísmo. Para condená-lo, seria necessário, primeiro, suprimir o clima moral que atualmente envolve o mundo novo: a atmosfera democrática asfixiaria qualquer tentativa de renascença da fauna dinástica; em segundo lugar, tornar-se-ia indispensável que, à reação contra as correntes, que julgo naturais, se juntasse algum poder divino ou sobrenatural, que obliterasse a noção de lei, universalmente adquirida. (Araripe Júnior, 1966b, p. 309)

Neste caso, Araripe invertia a relação de universalidade da doutrina e do continente. Não se tratava de uma doutrina imposta a um continente, mas de um continente que manifestava em todas as suas forças morais a novidade da ruptura e dos valores de uma história a realizar-se por meio de uma lei com 
validade universal. A força de lei da democracia adviria de correntes naturais manifestadas na história. Se o futuro à contingência pertencia, essa contingência era controlada por uma força que faria do sentido de independência nacional a pedra de toque da história das Américas.

\section{CONSIDERAÇÕES FINAIS: A AUTONOMIA}

\section{E A HETERONOMIA COMO APORIAS DA NAÇÃO}

Como podemos verificar, os discursos que Eduardo Prado e Araripe Júnior fizeram acerca do Brasil no contexto finissecular eram caracterizados pelo selo da polêmica. Autonomia, dependência e independência eram conceitos que reapareciam em suas falas como um tipo de problema permanente. Em discursos fundados nas filosofias da história como um modo de apreensão total do devir passado, presente e futuro, sobretudo na ideia de civilização brasileira como parte da história do Ocidente, eles tentaram definir o Brasil e aqueles exteriores constitutivos de significação da nação, um tipo de história de cada nação que tinha sua historicidade própria e uma ação central a desenvolver-se nos modos de produção do conhecimento histórico e político sobre a nação. Ainda poderia somar-se uma aporia às polêmicas entre eles: tanto Eduardo Prado quanto Araripe Júnior pensaram a autonomia do Brasil como um processo que se realizava desde a sua independência política. Prado evocou a tradição como um modo de manter o Brasil no rumo da civilização, o que para ele se constituía como a preservação da civilização monárquica de ascendência portuguesa. Haveria uma espessura de duração em relação à tradição ibérica que deveria ser conservada, sob o risco de perda da possibilidade de autodeterminação - o continuar a ser o que se era para ser alguma coisa. Se as sociedades deveriam ser regidas por leis saídas de sua raça e do seu desenvolvimento natural que estavam acima da nação, ou se uma nação deveria obedecer à lei de reformar-se dentro de si mesma, como ela poderia ser autodeterminada, a não ser por um ato autorreferencial de constituição do eu nacional que marcaria o início enquanto tal? Araripe, mesmo chegando a conclusões distintas de seu antípoda, pensava que a autonomia do Brasil estava diretamente vinculada a uma lei que estava acima da nação. Nos dois autores, uma reivindicação constante de independência e de autonomia. E nos mesmos dois autores, a presença contínua da heteronomia e da dependência. $\mathrm{O}$ que eles pareciam fazer, ao mobilizar um discurso sobre a autodeterminação nacional, era reafirmar constantemente a força de uma ordem (natureza, tradição, devir) da 
qual não se escaparia. A aporia que surgia no pensamento dos dois autores é que tanto a mobilização de uma permanência da tradição lusitana com a monarquia quanto a inexorabilidade da lei democrática dos povos que superaria o passado monárquico fundamentavam-se em um princípio heterônomo de constituição da autodeterminação nacional. Em última análise, tanto em Prado quanto em Araripe, todo o esforço para definir a nação como autônoma residiu na manutenção de algum tipo de heteronomia.

No Brasil da virada para o século XX, a atmosfera intelectual era permeada por um conjunto de problemas sociais, culturais, econômicos e políticos que estavam estreitamente vinculados às chamadas crises valorativas, morais e institucionais do que se denominava nação. Essas questões não ficaram fora da agenda de discussões que Eduardo Prado e Araripe Júnior travaram nesse contexto. Eduardo Prado via no presente uma decadência e uma perda da autonomia nacional brasileira diante da aproximação do Brasil aos Estados Unidos. Araripe Júnior, pelo contrário, entendia ser exatamente a manutenção dos vínculos com o passado que levaria o Brasil a manter-se atrelado aos valores de dependência nacional. Para um, a independência e a autonomia estavam lançadas na possibilidade de um retorno ao passado; para o outro, elas eram uma conquista do presente, que deveria ser aprofundada no futuro. Para um, o passado era a redenção e o futuro a escravidão; para o outro, o passado era a escravidão e o futuro a redenção. Em comum, nos dois autores, residia uma inquietação diante das mais diversas ameaças à autonomia nacional do Brasil e que foram alavancadas pela presença dos Estados Unidos na realidade do continente, o que marcava seu pensamento fundamentalmente pelo sentido de uma crise no presente que mobilizava os tempos do passado e do futuro. Com os discursos acerca dos sentidos da autodeterminação nacional, Eduardo Prado e Araripe Júnior tentaram preencher um significante que nós chamamos Brasil, dentro do qual "couberam" diversas realidades que exigiam decisões e posicionamentos desses intelectuais. Passados mais de 70 anos de independência do Brasil em relação a Portugal, a questão da autonomia nacional aparecia em diferentes contornos no pensamento desses intelectuais, uma pergunta pelo sentido de ser que mobilizou e ainda mobiliza distintos projetos, expectativas, desilusões e esperanças sobre a nação e sobre as fronteiras que demarcam sua autonomia e sua heteronomia, sua dependência e sua independência. 


\section{REFERÊNCIAS}

ALONSO, Ângela. Arrivistas e decadentes: o debate político-intelectual brasileiro na primeira década republicana. Novos Estudos, São Paulo, n. 85, p. 131-148, nov. 2009.

ARARIPE JÚNIOR, Tristão de Alencar. Americanismo. In: COUTINHO, Afrânio (ed.). Obra crítica de Araripe Júnior. Rio de Janeiro: Casa Rui Barbosa/Ministério da Educação e Cultura, 1963c. p. 93-100.

ARARIPE JÚNIOR, Tristão de Alencar. O combate naval de 16 de abril. In: COUTINHO, Afrânio (ed.). Obra crítica de Araripe Júnior. Rio de Janeiro: Casa Rui Barbosa/Ministério da Educação e Cultura, 1963b. p. 83-91.

ARARIPE JÚNIOR, Tristão de Alencar. Comentários à constituição federal brasileira. In: COUTINHO, Afrânio (ed.). Obra crítica de Araripe Júnior. Rio de Janeiro: Casa Rui Barbosa/Ministério da Educação e Cultura, 1966c. p. 23-63.

ARARIPE JÚNIOR, Tristão de Alencar. A Doutrina de Monroe. In: COUTINHO, Afrânio (ed.). Obra crítica de Araripe Júnior. Rio de Janeiro: Casa Rui Barbosa/ Ministério da Educação e Cultura, 1966b. p. 305-340.

ARARIPE JÚNIOR, Tristão de Alencar. O livro do Padre Severiano. In: COUTINHO, Afrânio (ed.). Obra crítica de Araripe Júnior. Rio de Janeiro: Casa Rui Barbosa/ Ministério da Educação e Cultura, 1966a. p. 151-162.

ARARIPE JÚNIOR, Tristão de Alencar. Sílvio Romero polemista. In: COUTINHO, Afrânio (ed.). Obra crítica de Araripe Júnior. Rio de Janeiro: Casa Rui Barbosa/ Ministério da Educação e Cultura, 1963a. p. 271-332.

ARMANI, Carlos H. Discursos da nação: historicidade e identidade nacional no Brasil em fins do século XIX. Porto Alegre: Ed. PUCRS, 2010.

AXT, Gunter; SCHÜLER, Fernando (org.). Intérpretes do Brasil: cultura e identidade. Porto Alegre: Artes e Ofícios, 2004.

AZEVEDO, Fernando. A cultura brasileira. 6. ed. Brasília: Ed. UnB; Rio de Janeiro: Ed. UFRJ, 1996.

BETHELL, Leslie. O Brasil e a ideia de "América Latina" em perspectiva histórica. Estudos Históricos, Rio de Janeiro, v. 22, n. 44, p. 289-321, jul./dez. 2009.

BOTELHO, André; SCHWARCZ, Lilia Moritz (org.). Um enigma chamado Brasil: 29 intérpretes e um país. São Paulo: Companhia das Letras, 2009.

BROCA, Brito. A vida literária no Brasil: 1900. 4. ed. Rio de Janeiro: J. Olympio Ed.: Academia Brasileira de Letras, 2005.

CAIRO, Luiz Roberto V. O crítico Araripe Júnior e sua eventual história da literatura brasileira. Navegações, Porto Alegre, v. 6, n. 1, p. 31-36, jan./jun. 2013.

CASTRO, Fernando Vale. Pensando um continente: a Revista Americana e a criação de um projeto cultural para a América Latina. Rio de Janeiro: Mauad X: Faperj, 2012. 
COUTINHO, Afrânio. Prefácio. In: COUTINHO, Afrânio (ed.). Obra crítica de Araripe Júnior. Rio de Janeiro: Casa Rui Barbosa/Ministério da Educação e Cultura, 1970. p. VII-XV.

DERRIDA, Jacques. Posições. Tradução de Tomaz Tadeu da Silva. Belo Horizonte: Autêntica, 2001.

DUMONT, Louis. O individualismo: uma perspectiva antropológica da ideologia moderna. Tradução de Álvaro Cabral. Rio de Janeiro: Rocco, 1985.

FELGUEIRAS, Carmen Lúcia T. Os arquitetos do futuro: os Estados Unidos segundo Monteiro Lobato e Eduardo Prado. Estudos Históricos, Rio de Janeiro, v. 1, n. 27, p. 141-165, 2001.

GIAROLA, Flávio Raimundo. Os "pastores guerreiros": jesuítas, catolicismo e história no pensamento monarquista-católico. E-hum - Revista Científica das áreas de História, Letras, Educação e Serviço Social do Centro Universitário de Belo Horizonte, v. 7, n. 1, p. 71-78, jan./jul. 2014.

HEGEL, Georg W. F. Filosofia da história. Tradução de Maria Rodrigues e Hans Harden. 2. ed. Brasília: Ed. UnB, 2008.

IPIRANGA, Sarah Diva da S. Nacionalismo em garde: a postura crítica de Araripe Jr. Linguagem em (Re)vista, Niterói, v. 11, n. 21, p. 140-148, jan./jun. 2016.

JANOTI, Maria de Lourdes M. Os subversivos da república. São Paulo: Brasiliense, 1986.

LEONZO, Nanci. A historiografia brasileira anti-republicana: a obra de Eduardo Prado. Revista do Instituto de Estudos Brasileiros, São Paulo, n. 27, p. 103-112, 1987.

MOISÉS, Massaud. História da literatura brasileira: realismo e simbolismo. 2. ed. São Paulo: Cultrix, 2017.

MOTA, Lourenço Dantas (org.). Introdução ao Brasil: um banquete no trópico. vol. 2. 2. ed. São Paulo: Senac São Paulo, 2002.

NODARI, Alexandre. Modernismo obnubilado: Araripe Jr. precursor da antropofagia. S. d. Disponível em: http://www.culturaebarbarie.org/NodariPUC.pdf. Acesso em: 10 jan. 2019.

OLIVEIRA, Lúcia Lippi. A questão nacional na Primeira República. São Paulo: Brasiliense, 1990.

OLIVEIRA, Rodrigo Perez. A comparação entre os regimes retóricos antigo e moderno no pensamento político conservador de Eduardo Prado (1879-1901). Revista de História Comparada, Rio de Janeiro, v. 10, n. 1, p. 83-118, 2016.

OLIVEIRA, Rodrigo Perez. O conservadorismo do jovem Eduardo Prado: um exercício de história intelectual (1878-1879). Faces da História, Assis, v. 2, n. 1, p. 236-257, jan./jun. 2015.

OLIVEIRA LIMA, Manuel de. Nos Estados Unidos: impressões políticas e sociais. Brasília: Senado Federal, Conselho Editorial, 2009. 
PERRONE-MOISÉS, Leyla. Vira e mexe nacionalismo: paradoxos do nacionalismo literário. São Paulo: Companhia das Letras, 2007.

POCOCK, John. Linguagens do ideário político. Tradução de Fábio Fernandez. São Paulo: Edusp, 2003.

PRADO, Eduardo. Discurso (Em comemoração da fundação do Instituto Histórico e Geográfico de São Paulo). In: PRADO, Eduardo. Coletâneas. São Paulo: Tipografia Salesiana, 1906. p. 114-144.

PRADO, Eduardo. A ilusão americana. 3. ed. São Paulo: Brasiliense, 1961.

PRADO, Eduardo. Mais uma ilusão desfeita. In: PRADO, Eduardo. Coletâneas. São Paulo: Tipografia Salesiana, 1904a. p. 401-411.

PRADO, Eduardo. A ruína financeira da República. In: PRADO, Eduardo. Coletâneas. São Paulo: Tipografia Salesiana, 1904b. p. 37-48.

PRADO, Eduardo. Três fatos. In: PRADO, Eduardo. Coletâneas. São Paulo: Tipografia Salesiana, 1904c. p. 418-427.

QUEIROZ, Suely R. R. de. Os radicais da República. São Paulo: Brasiliense, 1986.

QUINE, Williard. De um ponto de vista lógico. Tradução de Antonio Ianni Segatto. São Paulo: Ed. Unesp, 2011.

REIS, José Carlos. As identidades do Brasil: de Varnhagen a FHC. 6. ed. Rio de Janeiro: Ed. FGV, 2003.

REIS, José Carlos. As identidades do Brasil 2: de Calmon a Bomfim. Rio de Janeiro: Ed. FGV, 2006.

RENAUT, Alain. O indivíduo: reflexão acerca da filosofia do sujeito. Tradução de Elena Gaidano. 2. ed. Rio de Janeiro: Difel, 2004.

SALDANHA, Nelson N. História das idéias políticas no Brasil. Brasília: Senado Federal, 2001.

SKIDMORE, Thomas. O Brasil visto de fora. Tradução de Susan Semler et al. 2. ed. Rio de Janeiro: Paz \& Terra, 2001.

\section{NOTAS}

${ }^{1}$ Conforme Derrida (2001, p. 40), o sentido é constituído, em toda a sua extensão, de um tecido de diferenças, "na medida em que há já um texto, uma rede de remessas textuais a outros textos, uma transformação textual na qual cada 'termo' pretendidamente 'simples' é marcado pelo rastro de outro, a interioridade presumida do sentido é, já, trabalhada por seu próprio exterior. Ela se dirige já e sempre, para fora de si”. Ao aplicarmos o pensamento de Derrida para o contexto dos jogos de linguagem que marcavam e demarcavam a diferença interna e externa da nação no Brasil finissecular, pensamos que o conceito de exterior constitutivo pode servir para colocar como problema aquelas sobras ou sombras que marcam o discurso, de modo que ele seja constituído pelo signo da falta, como também da ameaça. Gostaríamos, contudo, de reter, para os propósitos deste texto, mais a ideia do 
"rastro de um outro" que penetra no discurso do que a ideia de remessas textuais, ainda que elas sejam importantes para os modos de apropriação do discurso entre os diferentes autores. As razões para certa reserva no uso dessa expressão são apresentadas no corpo do texto.

${ }^{2} \mathrm{O}$ leitor interessado na discussão contextual específica sobre a relação do Brasil com os Estados Unidos na história intelectual brasileira poderá consultar Skidmore (2001, p. 3352).

${ }^{3}$ Uma primeira aproximação, incipiente, aos discursos contrastantes de Prado e de Araripe foi apresentada em livro (ARMANI, 2010). Naquela ocasião, pouco discutimos o tema da autodeterminação nacional no pensamento de Prado e de Araripe, especialmente no caso do segundo. Além disso, as premissas teóricas das quais partimos eram fundamentalmente diferentes daquelas que estamos utilizando no presente artigo. Numa primeira apropriação da discussão desses autores, praticamente tínhamos somente a preocupação de pensar seus discursos no âmbito dos desdobramentos do texto sobre ele mesmo. A referência a Quine e Pocock, mencionada no corpo do artigo, é indicador importante de uma mudança de perspectiva teórica que realizamos neste artigo, especialmente no modo como temos pensado a história intelectual e seus desdobramentos para além da virada linguística.

${ }^{4}$ Não consideramos tais perspectivas como as únicas existentes acerca dos discursos da dependência e da independência nacionais, nem os autores que mencionamos como seus portadores exclusivos. Não se trata de apresentar, portanto, uma lista exaustiva de autores que defenderam tais discursos, mas apenas uma amostra do pensamento de autores expressivos da virada para o século XX. Para uma leitura mais abrangente da história intelectual desse período, conferir: Reis (2003; 2006); Botelho; Schwarcz (2009); Azevedo (1996); Broca (2005); Saldanha (2001); Skidmore (2001); Oliveira (1990); Mota (2002); Perrone-Moisés (2007); Moisés (2017); Janoti (1986); Queiroz (1986); Axt; Schüler (2004); Alonso (2009). Sobre os autores especificamente, é mais fácil encontrar trabalhos sobre Eduardo Prado do que sobre Araripe Júnior: Para o primeiro, ver: Leonzo (1987); Felgueiras (2001); Skidmore (2001); Giarola (2014); Oliveira (2015; 2016). No caso de Araripe, ver: Nodari (s.d.); Ipiranga (2016); Cairo (2013). Não fosse a iniciativa da Casa de Rui Barbosa de publicar a obra crítica de Araripe, nos anos 1960, talvez sua obra fosse ainda mais desconhecida. Cabe destacar que, na relação de trabalhos que tratam de intérpretes do Brasil citados acima, nenhum dos livros tem capítulo ou artigo dedicado ao pensamento de Araripe.

${ }^{5}$ Tomo a ideia de singular-coletivo de Dumont, que exprime uma aporia da nação como coleção de indivíduos e indivíduo coletivo. Ao longo de seu artigo sobre a variante nacional do indivíduo, Dumont apresenta a relação do individualismo com a nação (DUMONT, 1985, p. 139).

${ }^{6}$ A independência, neste caso, poderia ser confundida com a autonomia ou como parte de um processo fundamental para a conquista da autonomia nacional ou até mesmo o ato fundacional que permitiria à nação tornar-se autodeterminada. Sabemos que autonomia e independência não são exatamente sinônimos. Sua substituição salva veritate dificilmente poderia manter-se sem prejuízo de compreensão daquilo que tais palavras significam. Tal- 
vez seja possível mesmo sugerir que, tanto em Prado quanto em Araripe, a independência era um dos predicados fundamentais da autonomia. Uma nação autodeterminada seria aquela que, tendo independência, não precisaria obedecer às ordens daquilo que lhe era exterior, de modo a fundar a normatividade da ordem nacional a partir de si. Ao longo das citações, creio que ficará claro para o leitor que os autores que investigamos usam os conceitos de autonomia e de independência como sinônimos. Renaut (2004) sugere que se faça uma distinção não somente entre indivíduo e sujeito, como também entre independência e autonomia.

${ }^{7}$ Segundo Alonso, tal período é um dos mais tensos dos primeiros anos republicanos, quando a "conjuntura de radicalização política e guerra civil imprimiu mudanças no debate público", de modo que "quem carregava nas tintas contra o governo tinha dois destinos, a prisão [...] ou o exílio" (ALONSO, 2009, p. 144). Logo após a apreensão do seu livro, o exílio acabou por ser o destino de Prado.

${ }^{8}$ Ver, a esse respeito, os capítulos: "Gênese II. A categoria política e o Estado a partir do século XIII" e "Uma variante nacional. O povo e a nação em Herder e Fichte" em Dumont (1985).

${ }^{9}$ A aproximação do Brasil aos demais países da América do Sul e Central foi realizada pelo autor somente para fins de distanciamento do Brasil aos Estados Unidos e a qualquer forma republicana, ou seja, como um modo de distanciar-se também das demais nações latino-americanas. Ela teve mais o sentido pedagógico de demonstrar como tais Estados nacionais haviam fracassado ao implantarem a república do que ser um modelo de consciência latino-americana que viria a se desenvolver posteriormente a partir da ideia de Terceiro Mundo (ver PRADO, 1961, p. 44-97). A respeito da discussão sobre essa relação entre Brasil e América Latina, ver Bethell (2009).

${ }^{10}$ Como afirma Alonso, "por cansaço ou fracasso, muitos se insularam da política institucional. Em 1897, ex-reformistas, ex-monarquistas, ex-republicanos, mesmo ex-jacobinos criaram sua própria república, a das letras. Na Academia Brasileira de Letras, fundiram suas identidades políticas contrastivas, de monarquia-aristocrata e de republicano-ascendente, numa nova identidade compartilhada, a de 'intelectuais"” (ALONSO, 2009, p. 147).

${ }^{11}$ As críticas de Araripe a Eduardo Prado não foram as únicas publicadas na Revista Americana. De acordo com Castro, outros intelectuais, preocupados em reforçar o pan-americanismo como valor, teceram críticas ao escritor monarquista (ver CASTRO, 2012, p. 6768).

${ }^{12}$ Não estou propondo um estudo da recepção das ideias de Eduardo Prado, o que implicaria uma investigação mais aprofundada de seus leitores a fim de poder mapeá-la. Entretanto, cabe notar que Araripe Júnior foi um leitor contemporâneo e atento à obra de Prado, ou um escritor-leitor. Como sugere Pocock, "a história do discurso está interessada nos atos de fala que se tornam conhecidos e que evocam respostas, com elocuções que são modificadas à medida que se tornam perlocuções, conforme a maneira como os receptores respondam a elas, e com respostas que tomam a forma de novos atos de fala e de textos em resposta. O próprio leitor se torna um autor, e é exigido do historiador um complexo de 
tipo Rezeptionsgeschichte. Nesse ponto, nos movemos do autor para o leitor, mas o leitor visto como autor. Porque, caso não sejam efetuadas no meio - discurso escrito ou publicado - que o próprio autor empregou, as respostas do leitor nada terão a nos dizer" (POCOCK, 2003, p. 45).

${ }^{13}$ É conhecida a separação que Hegel fez entre povos com história e povos sem história. Em relação às Américas, vejamos uma parte de seu texto: “A América é, portanto, a terra do futuro, na qual se revelará, em tempos vindouros, o elemento importante da história universal - talvez a disputa entre América do Norte e do Sul. É uma terra de aspirações para todos que deixam o museu de armas históricas da velha Europa [...] Cabe à América abandonar o solo sobre o qual se tem feito a história universal. O que nela aconteceu até agora nada mais é do que o eco do Velho Mundo, a expressão de uma vida estrangeira [...]. Por ser a terra do futuro, a América não nos interessa aqui, pois, no que diz respeito à história, nossa preocupação é com o que foi e com o que é” (HEGEL, 2008, p. 79). O texto de Hegel é, no mínimo, ambíguo. Apesar de valorar negativamente a América e, especialmente, a América do Sul, sua recusa de história para tal continente se relacionava a uma questão temporal, uma escala que separaria o passado do futuro.

Artigo recebido em 22 de maio de 2019.

Aprovado em $1^{\circ}$ de abril de 2020.

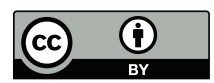

